\title{
DICKES KNIE BEIM JOGGEN
}

E in 52-jähriger, sehr sportlicher Gastronom kommt zu mir wegen Knieschmerzen und -schwellung rechts beim Joggen und wegen eines Kältegefühls in der rechten Wade, unabhängig vom Sport.

Als Hauptsymptompunkt finde ich den Punkt des rechten Knies, außerdem behandle ich einige Narbenstörherde, die ich über die Ohrreflexzonen auffinden kann. Beide Iliosakralgelenke sind blockiert sowie der oberste Halswirbel C1 rechts. Ich richte beides ein, mit den Händen, aber auch mit Unterstützung der Nadeln an den zugehörigen Reflexzonen am Ohr.

Nach drei Behandlungen fühlt sich der Patient sehr wohl - aber die Problematik im rechten Bein bleibt.

Da mir das Kältegefühl in der Wade doch langsam verdächtig erscheint, lasse ich den Patienten in einer neurologischen Klinik untersuchen, ohne pathologischen Befund.

Ich habe noch einen Pfeil im Köcher:Von Anfang an war mir ein Zahn als Herd aufgefallen. Zahn 14, wurzelbehandelt, im Röntgen vom Zahnarzt als unauffällig beurteilt (Abb. 1).

Ich hatte den Zahn im sogenannten „verdeckten“ System gefunden, mit der Zahn-Bahr-Frequenz 7 des Lasers unter RAC-Kontrolle (Nogier-Puls). Er stört in diesem System mäßig stark (auf PE1) und bewegt sich in der Stärke weder durch Nadeln noch durch Laser weiter nach unten (d.h. er wurde nicht leichter oder weniger störend). Dies heißt üblicherweise, dass man die Störwirkung durch Nadeln oder sonstige konservative Maßnahmen nicht weiter reduzieren kann, weil die Keimlast im Wurzelkanal zu hoch ist und sich nach apikal ausbreitet.

Um einen Zusammenhang Zahn - Knie zu klären, nutze ich eine der wichtigsten Techniken der Ohrakupunktur: Ich prüfe nach, ob vielleicht der Kniepunkt ebenfalls RAC-Resonanz auf die Frequenz 7 des Lasers hat. Und siehe da, so ist es. Das bedeutet, wenn ich den Kniepunkt (oder das Knie selbst) mit der Zahnfrequenz 7 anstrahle

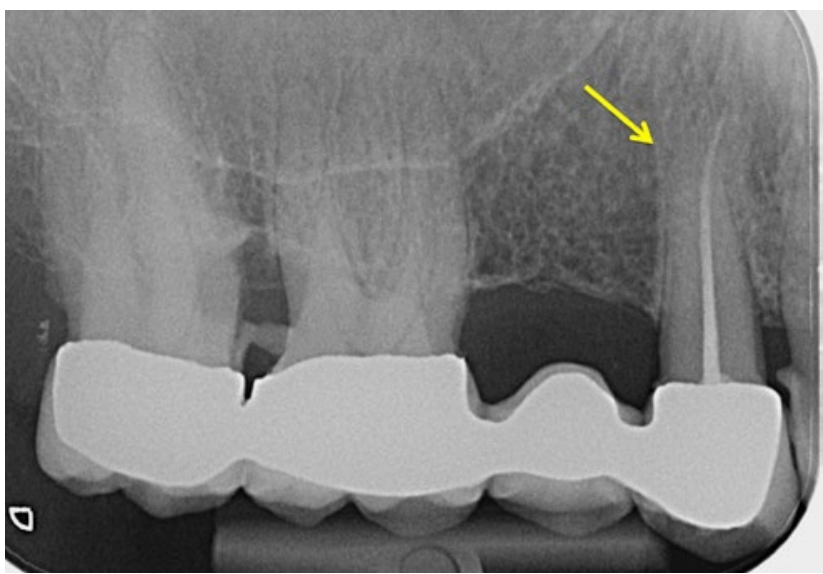

Abb. 1: Zahn 14,WF

(5 mW), erhalte ich einen RAC (Nogier-Puls). Ich schlieBe daraus, dass der Zahn 14 nicht nur stört, sondern dass er an dem Knieschmerz ursächlich beteiligt ist.

Ich empfehle dem Patienten die Durchführung einer sogenannten Endodontie, einer Revision der Wurzelfüllung unter dem Mikroskop bei einem Spezialisten.

Bei der darauffolgenden Akupunktursitzung berichtet der Patient mir, dass direkt nach der endodontischen Behandlung des Zahnes sein Knieschmerz verschwunden sei! Und er sei diese Woche bereits $80 \mathrm{~km}$ gejoggt. Ohne Knieschmerz, ohne Schwellung. SolcheVerläufe erstaunen mich selbst immer wieder.

Leider kann man beherdete Zähne auf dem Röntgenbild oft nicht als solche erkennen. Lechner, München, hat schon vor vielen Jahren als erster herausgefunden, dass erst $40 \%$ der Knochensubstanz weg sein müssen, bis man auf einem OPG eine Veränderung sehen kann, die einen Anhalt für eine Pathologie hergibt.

Unsere Form der Testung kann - korrekt ausgeführt - in den meisten Fällen eine Beherdung eines Zahnes aufdecken. Es lohnt sich, diese Testtechniken zu lernen (Laserkurse, ab Stufe 3 Ohrakupunktur).

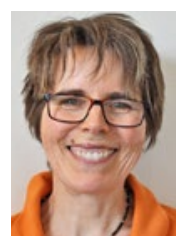

Dr. med. Beate Strittmatter

FA für Allgemeinmedizin, Akupunktur, Sportmedizin, Naturheilverfahren

Ausbildungsleitung Ohrakupunktur

Quellenstr.19, 66121 Saarbrücken

Strittmatter@t-online.de 